\title{
Acute Kidney Injury and Extracorporeal Membrane Oxygenation: Review on Multiple Organ Support Options
}

Lorenzo Foti ${ }^{1,2}$

Gianluca Villa ${ }^{1,2}$

Stefano Romagnoli ${ }^{1,2}$

Zaccaria Ricci ${ }^{1,3}$

'Department of Health Sciences, Section of Anesthesiology and Intensive Care, University of Florence, Florence, Italy; ${ }^{2}$ Department of Anesthesia and Intensive Care, AOU Careggi, Florence, Italy; ${ }^{3}$ Pediatric Intensive Care Unit, Meyer Children's University Hospital, Florence, Italy
Correspondence: Zaccaria Ricci $\mathrm{Tel}+393393799848$

Email zaccaria.ricci@gmail.com

\begin{abstract}
Extracorporeal membrane oxygenation (ECMO) is a temporary life support system used to assist patients with life-threatening severe cardiac and/or respiratory insufficiency. Patients requiring ECMO can be considered the sickest patients admitted to the intensive care unit (ICU). Acute kidney injury (AKI) represents a frequent complication during ECMO, affecting up to $70 \%$ of patients, with multifactorial pathophysiology and an independent risk factor for mortality. Severe AKI requiring Continuous Renal Replacement Therapy (CRRT) occurs in $20 \%$ of ECMO patients, but multiple indications and different timing may imply a significantly higher application rate in different centers. CRRT can be run in parallel to ECMO through different vascular access, or it can be conducted in series by connecting the circuits. Anticoagulation of ECMO is typically managed with systemic heparin, but several approaches can be applied for the CRRT circuit, from no anticoagulation to the addition of intra-filter heparin or regional citrate anticoagulation. The combination of CRRT and ECMO can be considered a form of multiple organ support therapy, but this approach still requires optimization in timing, setup, anticoagulation, prescription and delivery. The aim of this report is to review the pathophysiology of AKI, the CRRT delivery, anticoagulation strategies and outcomes of patients with AKI treated with ECMO.
\end{abstract}

Keywords: extracorporeal membrane oxygenation, acute kidney injury, continuous renal replacement therapy, multiple organ support therapy, anticoagulation, mortality

\section{Introduction}

Extracorporeal membrane oxygenation (ECMO) is a temporary life support system used to assist patients with life-threatening severe cardiac and/or respiratory insufficiency. It takes blood out of the body, removes carbon dioxide, adds oxygen, and pumps it back into the body. The Extracorporeal Life Support Organization (ELSO) guidelines ${ }^{1}$ indicate that it should be considered a rescue therapy when the risk of mortality would be $80 \%$ or greater if not applied. ECMO is divided into two systems: veno-venous ECMO (VV-ECMO), indicated for patients with respiratory failure but preserved cardiac activity and veno-arterial ECMO (VA-ECMO), indicated in refractory cardiogenic shock and it provides both pulmonary and circulatory support (VAECMO is also indicated as ExtraCorporeal Life Support -ECLS). ECMO has been applied even outside the intensive care unit (ICU), ie, in the emergency department where it can be attempted as an extracorporeal cardiopulmonary resuscitation, or in out-of-hospital cardiac arrest cases. More recently, a modified ECMO setup has been 
proposed after cardiac death to perfuse the liver and/or the kidneys as a bridge to organ procurement. ${ }^{2,3}$

Even if there are no absolute contraindications to ECMO application, the presence of nonrecoverable comorbidities should imply to refrain from starting such an invasive and challenging therapy. Relative contraindications include major central nervous system damage, terminal malignancy, and old age. ${ }^{1}$

Patients requiring ECMO represent the sickest ICU patients and are at high risk of developing Multiple Organ Dysfunction Syndrome (MODS). Acute Kidney Injury (AKI) is one of the most frequent complications ${ }^{4,5}$ affecting these patients and timely diagnosis and treatment of renal dysfunction are potential options to improve their outcomes and decrease mortality.

\section{Epidemiology of AKI and Indications to Renal Replacement Therapy in ECMO Patients}

Up to $75 \%$ of ECMO patients ${ }^{6-10}$ show signs of renal dysfunction (Table 1), although incidences may vary depending on patients' categories, treating centers, and AKI definitions. ${ }^{11-13}$ About half of patients with AKI undergo a dialytic treatment during ECMO. AKI is often associated with fluid overload (FO), and both are associated with increased mortality in critically ill patients, including those in ECMO. ${ }^{6,14-16}$

During ECMO, large-volume fluid therapy is frequently needed to optimize hemodynamics, due to hypotension that may be secondary to hypovolemia and reduced vascular systemic resistances. In many cases, fluids are administered to minimize the chattering of the circuit and to treat bleeding complications. ${ }^{8}$ It is clear that if the capacity of the kidneys to cope with such important demand is altered, fluid homeostasis is rapidly and significantly compromised. In these cases, FO itself becomes one of the causes of renal dysfunction (renal congestion), and it certainly is one of the main contributors to patients' reduced survival. Timely and aggressive treatment of FO is required in ECMO patients with renal dysfunction. In clinical practice, clinically relevant fluid accumulation is one of the most important factors to consider as a sign of renal dysfunction. In a survey involving 65 international ECMO centers, the indications for starting CRRT on ECMO were FO treatment (43\%), FO prevention (16\%), AKI (35\%) and electrolyte disturbances (4\%). ${ }^{17}$ In a wellconducted observational study by Hoover et al, in $62 \%$ of all patients receiving CRRT/ECMO the primary indication was fluid overload (62\%) without apparently established renal insufficiency. ${ }^{18}$ Recently, in a retrospective study evaluating 357 children with ECMO requiring CRRT, the primary indications for the initiation of CRRT were FO or FO prevention (84.6\%), AKI (11.2\%), electrolyte abnormalities $(1.1 \%)$, toxin removal $(1.1 \%)$, and other $(2 \%) .{ }^{19}$ In a retrospective study of 63 ECMO patients requiring CRRT, Antonucci et al reported the following indications: acidosis $(n=48)$, excessive urea levels $(n=7)$, hyperkalemia $(n=4)$, and fluid overload $(n=4){ }^{7}$ However, during ECMO, as for other critically ill patients, the absolute indications for CRRT are the "renal indications" including uremia, acidosis, overdose/toxicity from a dialyzable drug/ toxin and electrolyte abnormalities. ${ }^{20}$

Currently available reports highlight that, in the vast majority of cases, AKI is present at the time of ECMO

Table I Epidemiology in Retrospective Studies Evaluating ECMO Patients with and without Renal Dysfunction

\begin{tabular}{|c|c|c|c|c|c|}
\hline Author & $\begin{array}{l}\text { AKI During } \\
\text { ECMO }\end{array}$ & $\begin{array}{l}\text { CRRT During } \\
\text { ECMO }\end{array}$ & $\begin{array}{c}\text { Population (ECMO } \\
\text { +CRRT) }\end{array}$ & $\begin{array}{c}\text { Mortality (Hospital } \\
\text { Mortality) }\end{array}$ & $\begin{array}{c}\text { Renal Recovery (at } \\
\text { Discharge) }\end{array}$ \\
\hline Dado et al $(2020)^{6}$ & $36 / 48(75 \%)$ & $48 / 92(46 \%)$ & 48 adults & $39.5 \%$ & $80 \%$ \\
\hline Antonucci et al $(2016)^{7}$ & $95 / 135(70 \%)$ & $63 / 135$ (47\%) & 63 adults & $60 \%$ & Not explored \\
\hline Schmidt et al $(2014)^{8}$ & $97 / 172(57 \%)$ & $103 / 172(60 \%)$ & 103 adults & $35 \% 3$-month mortality & Not explored \\
\hline Paden et al $(20 \mathrm{II})^{9}$ & $50 / 68$ (74\%) & I54/378 (4I\%) & I54 children & $56 \%$ & $96 \%$ \\
\hline Barbaro $(2020)^{10}$ & $247 / 779$ (32\%) & $444 / 1006$ (44\%) & 444 adults & Not explored & Not explored \\
\hline Deatrick $(202 I)^{14}$ & Not explored & $94 / 187$ (50\%) & 94 adults & $38.6 \%$ & $93 \%$ \\
\hline Hoover et al $(2008)^{18}$ & Not explored & $26 / 86(30 \%)$ & 26 children & $27 \%$ & $100 \%$ \\
\hline Wolf et al $(2013)^{23}$ & Not explored & $59 / 153(39 \%)$ & 59 children & $75 \%$ & Not explored \\
\hline Kielstein et al $(2012)^{24}$ & Not explored & $120 / 200(60 \%)$ & 120 adults & $83 \% 3$-month mortality & Not explored \\
\hline Wu et al $(2007)^{25}$ & Not explored & $18 / 45(40 \%)$ & 18 adults & $88 \%$ & Not explored \\
\hline Thajudeen et al $(2015)^{26}$ & Not explored & Not explored & 40 adults & $80 \%$ I-month mortality & $62.5 \%$ at I month \\
\hline Aubron et al $(2013)^{27}$ & Not explored & $6 \mathrm{I} / 105$ (58\%) & 61 adults & $37.3 \%$ & Not explored \\
\hline
\end{tabular}


cannulation or develops within $48 \mathrm{~h}$ from ECMO. ${ }^{13,21}$ Nevertheless, more prolonged ECMO support is associated with a higher risk of AKI development. ${ }^{22}$ Hence, renal replacement therapy is used between $30 \%$ and $60 \%$ of ECMO patients with severe AKI (Table 1), ${ }^{6-10,14,18,23-27}$ and CRRT is the most commonly used modality.

\section{Pathophysiology: AKI and ECMO}

Etiopathogenesis of AKI during ECMO treatment is multifactorial. ${ }^{11}$ Patient's pre-existing comorbidities (eg, chronic heart failure, chronic kidney disease, diabetes), the primary disease (respiratory failure, cardiac failure, sepsis) and their management (need for vasoactive support, chronic diuretic therapy, antibiotic therapy, contrast media) play a key role in the development of AKI. Furthermore, factors directly related to ECMO contribute to the development of AKI. One of the most important factors is the exaggerated inflammatory response due to the overproduction of cytokines that causes an unregulated host response (similar to that observed during sepsis). Contact of the blood components with the artificial surface of the bypass circuit activates the complement system with the release of $\mathrm{C} 3 \mathrm{a}$ and $\mathrm{C} 5 \mathrm{a} .{ }^{28}$ Activated complement factors induce the production of proinflammatory (IL1, IL 6, TNFalpha) and anti-inflammatory (IL10) cytokines. ${ }^{29,30}$ The result is an increased vascular permeability and endothelial dysfunction. Furthermore, during ECMO there is a high risk of bacterial translocation due to gut mucosa hypoperfusion. Endotoxin expressed by gram-negative bacteria induces pro-inflammatory interleukins release from innate immunity cells expressing toll-like receptor and endothelial cells. ${ }^{31}$ At the same time, these cytokines activate the coagulation cascade. Moreover, this leads to the disruption of the glycocalyx layer and alteration of the microcirculatory system of all the organs, including the kidneys.

Hemolysis is another factors directly related to the ECMO due to the red cell stress. ${ }^{32,33}$ During prolonged use of ECMO, the constant shear stress of the ECMO circuit can produce hemolysis with hemoglobinuria, which may itself induce kidney damage. ${ }^{34}$ Plasma-free haemoglobin $(\mathrm{fHb})$ and free iron contribute to Reactive Oxygen Species (ROS) damage to the kidney. ${ }^{35}$ Ischemia-reperfusion injury due to the hemodynamic changes at ECMO cannulation may represent a further key factor in the microcirculatory dysfunction leading to AKI. The reperfusion of hypoxic cells leads to leukocyte activation with local inflammation and ROS production inducing mitochondrial dysfunction. ${ }^{36}$ Other factors directly related to the renal damage are the absence of pulsatile flow and the need of multiple blood component transfusions. ${ }^{37}$ Finally, as already highlighted, FO itself before and during ECMO may increase the risk of AKI. ${ }^{8}$

\section{Timing of CRRT}

The right time to start CRRT during ECMO is a poorly studied field and to date there are no clinical trials specifically addressing this issue. Conflicting results are found in the literature. In a large meta-analysis on adult patients on ECMO the early initiation of CRRT seemed to increase the survival. ${ }^{38}$ Other studies performed in children on ECMO suggested that early start of CRRT is associated with improved outcomes. ${ }^{39,40}$ Instead, in a retrospective analysis of 153 cardiac ECMO children, 59 (39\%) received early CVVH (within 48 hours of ECMO initiation), and they were 3 times more likely to die during their hospitalization. ${ }^{23}$ Further studies, especially randomized clinical trials, are needed to better clarify the topic even if prospective research is very limited in this field. In patients receiving ECMO, as well as critically ill patients in general, the right timing to start CRRT should be evaluated on a case-by-case and daily basis considering the risks and benefits. It is well known that FO is a determining factor in higher mortality, especially in patients with heart and respiratory failure and it should be kept as one of the main triggers for a proactive CRRT start. As reported by the ELSO guidelines, the real goal is to keep the patient close to dry weight. CRRT should be promptly instituted when diuretic therapy is not effective with the aim of preventing or treating FO. ${ }^{19}$

\section{Delivery of CRRT to ECMO Patients}

During ECMO, all RRT modalities - continuous venovenous hemofiltration $(\mathrm{CVVH})$, continuous veno-venous hemodialysis (CVVHD), continuous veno-venous hemodiafiltration (CVVHDF) or slow continuous ultrafiltration (SCUF) can be selected and applied. There are different ways to combine ECMO and CRRT with associated advantages and disadvantages (Table 2), without a standard method recommended. ${ }^{41}$ In clinical practice, the decision often depends on local expertise and institutional protocols. Patients of all ages have been described to receive ECMO and CRRT: the in series - or integrated connection appears to be most common in children, ${ }^{42}$ whereas a parallel approach has been recommended in adults. $^{43}$ 
Table 2 Delivery of CRRT to ECMO Patients: Advantages and Disadvantages

\begin{tabular}{|c|c|c|c|}
\hline \multicolumn{2}{|l|}{ Approach } & \multirow[b]{2}{*}{\begin{tabular}{l}
\multicolumn{1}{c}{ Advantages } \\
- Absence of interference related \\
to pressure differences \\
- Standard CRRT prescription \\
- Standard CRRT circuit \\
management \\
- Combined anticoagulation \\
strategy (systemic + regional)
\end{tabular}} & \multirow{2}{*}{$\begin{array}{l}\text { Disadvantages } \\
\text { - Need of separate vascular access } \\
\text { - Risk of bleeding during the catheter placement } \\
\text { - Increased nursing efforts }\end{array}$} \\
\hline Parallel & $\begin{array}{l}\text { Separate CRRT and } \\
\text { ECMO circuit }\end{array}$ & & \\
\hline \multirow[t]{2}{*}{ Integrated } & In-line hemofilter & $\begin{array}{l}\text { - Low cost } \\
\text { - Easy set-up } \\
\text { - No need for separate vascular } \\
\text { access }\end{array}$ & $\begin{array}{l}\text { - No pressure monitoring } \\
\text { - Less precise ultrafiltration } \\
\text { - Requires external pump to control ultrafiltration } \\
\text { - Flow turbulences and risk of hemolysis }\end{array}$ \\
\hline & $\begin{array}{l}\text { Full CRRT circuit into } \\
\text { the ECMO circuit }\end{array}$ & $\begin{array}{l}\text { - Pressure monitoring } \\
\text { - More precise ultrafiltration } \\
\text { - No need for separate vascular } \\
\text { access }\end{array}$ & $\begin{array}{l}\text { - Exposure of the CRRT machine to pressures outside the safety } \\
\text { range ( }>\text { down time } \rightarrow<\text { delivered dose) } \\
\text { - Flow turbulences and risk of hemolysis } \\
\text { - Shunt within ECMO circuit } \\
\text { - CRRT circuit management } \\
\text { by an ECMO perfusion/circuit specialist }\end{array}$ \\
\hline
\end{tabular}

Abbreviations: CRRT, Continuous Renal Replacement Therapy; ECMO, ExtraCorporeal Membrane Oxygenation.

\section{Parallel Approach}

One possibility is to perform CRRT and ECMO independently, using separate vascular accesses and circuits. Considering that flows reached in the ECMO circuit are much higher than those reached in the CRRT circuit (approximately $4000-5000 \mathrm{~mL} / \mathrm{min}$ against $150-200 \mathrm{~mL} /$ $\mathrm{min}$ ), one advantage is the absence of interference between the two devices without concerns related to CRRT pressure alarms. A standard CRRT prescription can be applied, and the management of the CRRT circuit (eg, to change the filter) can be performed by the bedside nurse without the direct involvement of an ECMO perfusion/circuit specialist. A combined (systemic and regional) anticoagulation can be performed.

The disadvantages include the need for an additional central venous (dialysis) catheter, in patients who may not have additional sites for central venous cannulation available, added to all the associated complications, such as infection and thrombosis. Moreover, there might be an increased risk of bleeding during the catheter placement due to the anticoagulation required for ECMO.

\section{Integrated Approach}

Dialysis can be performed by introducing aonly filter (inline hemofilter) or afull C RRT machine into the ECMO circuit.

\section{In-Line Hemofilter}

The filter inlet is connected after the blood pump and the filter outlet before the pump (Figure 1A). The advantages of this method are the low cost, the easy setup and the absence of the need for a second device and separate vascular access. The disadvantages are the absence of pressure monitoring, a less precise ultrafiltration with limited solute clearance (an error up to $800 \mathrm{~mL} / \mathrm{die}^{44}$ ) requiring an external pump to control it, a high risk of hemolysis and enhanced systemic inflammation for the flow turbulences.

\section{RRT Machine and Circuit into the ECMO Circuit}

The CRRT inflow and outflow can be integrated into the ECMO circuit, before the oxygenator, in three different sections with different pressures: 1 . The limb of the ECMO circuit with positive pressure, after the centrifugal blood pump (Figure 1B); 2. The limb of the circuit with negative pressure, before the centrifugal blood pump (Figure 1C); 3. The CRRT inflow is connected to the limb of the ECMO circuit with positive and the outflow in the negative pressure side (Figure 1D). Unlike the inline hemofilter, this approach allows to monitor the pressures and guarantees a more precise ultrafiltration with an effective solute clearance, as demonstrated by Symons et al. $^{45}$ One of the most important disadvantages is the exposure of the CRRT machine to pressures outside the 

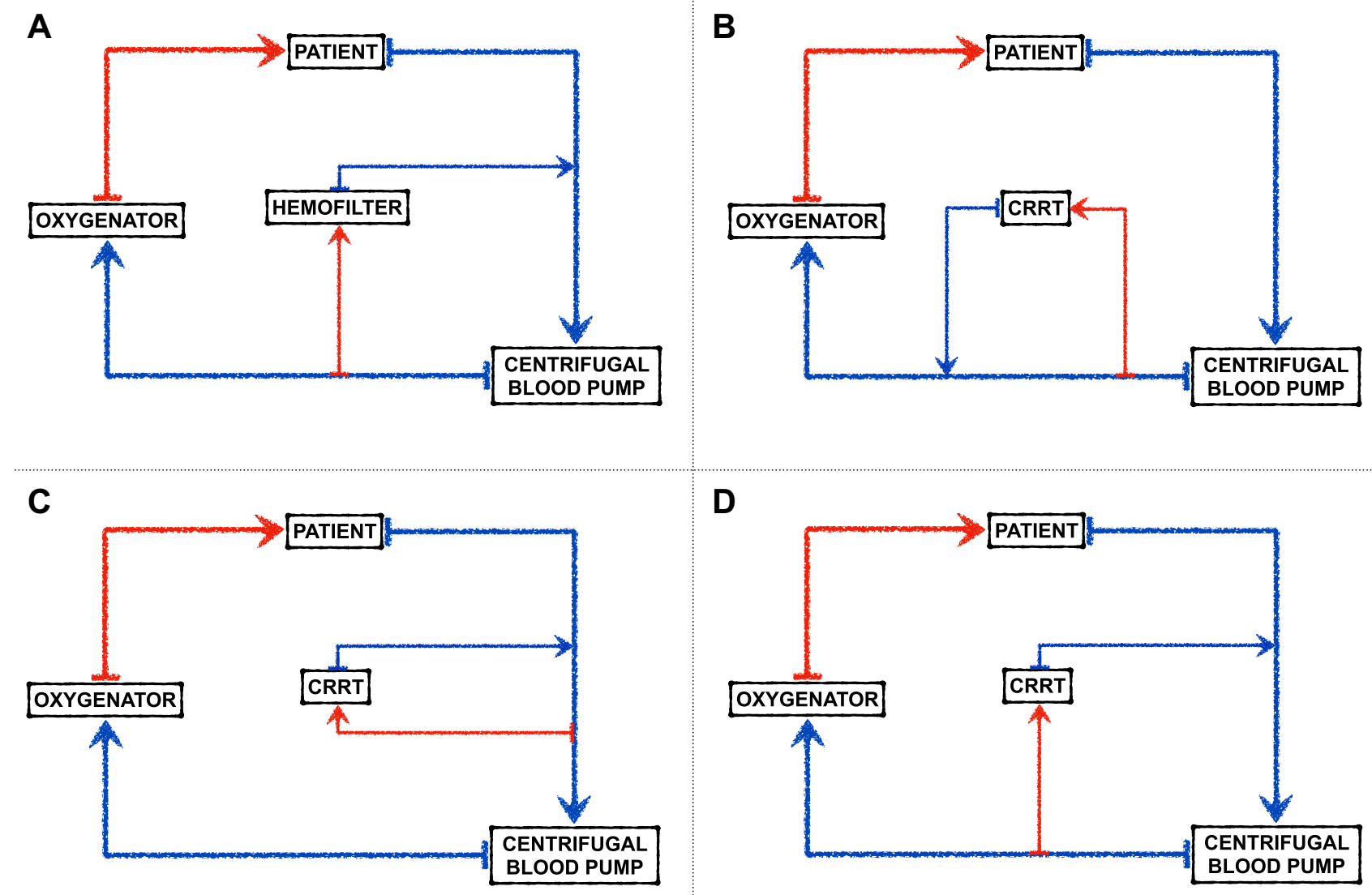

Figure I (A) In-line Hemofilter. (B) Full RRT circuit into the ECMO circuit: section of the circuit under positive pressure. (C) Full RRT circuit into the ECMO circuit: section of the circuit under negative pressure. (D) Full RRT circuit into the ECMO circuit: section of the circuit under positive and negative pressure.

Abbreviation: CRRT, Continuous Renal Replacement Therapy.

safety range. In some CRRT devices, these pressure changes might trigger the CRRT pressure alarms and often lead to repeated stops in treatment with an increase in down time and decreased delivered dose. However, third- and fourth-generation CRRT machines can adjust/ adapt the pressure ranges to the integrated setup and allow to safely run the dialytic session. Moreover, this method, as the inlet hemofilter, does not require any additional central vascular access. Still, it has a high risk of hemolysis and enhanced systemic inflammation for the flow turbulences. These specific aspects require further evaluation and dedicated studies in the future. Advantages and disadvantages of different approaches are listed in Table 2.

\section{Anticoagulation}

The contact between blood and the foreign surface of the ECMO circuit induces a pro-inflammatory and procoagulant response. Systemic anticoagulation is needed for the prevention of clot formation. ${ }^{46}$ Although the ELSO guidelines do not recommend a specific anticoagulant, systemic unfractionated heparin (UFH) is the most used one. ${ }^{47} \mathrm{UFH}$ is an indirect coagulation inhibitor. Indeed, it binds and increases antithrombin (AT) activity, which inactivates the formation of factor Xa and thrombin. Therefore, the efficacy of UFH depends on the AT concentration. Despite the UFH availability, low cost, and the presence of a specific antidote, ${ }^{1,48}$ many challenges can arise, such as heparininduced thrombocytopenia (HIT), heparin resistance, and variable response from heparin due to its binding to several plasma proteins, endothelial surface, and primarily by circulating platelets, which scavenge heparin by releasing platelet factor 4 (PF4) ${ }^{49,50}$ Direct thrombin inhibitors could be used as an alternative to heparin. Bivalirudin is a direct thrombin inhibitor with a short half-life and partial kidney clearance (about 20\%). ${ }^{49}$ Its use during ECMO has been successfully reported in the case of HIT. ${ }^{51}$ Recently, 
Rivosecchi et al ${ }^{52}$ performed a retrospective cohort study where they compared 162 patients receiving UFH with 133 patients receiving bivalirudin for anticoagulation on VV-ECMO. The bivalirudin group showed a decrease in clot formation in the ECMO circuit as well as a significant decrease in volume of blood product administration (red blood cells, plasma and platelet).

In a retrospective analysis of 135 AKI patients treated with bivalirudin for HIT, Tsu and Dagger demonstrated how the bivalirudin dose needed to reach a therapeutic activated partial thromboplastin time (aPTT) goal was lower with respect to patients with normal renal function. ${ }^{53}$ Specifically, the reduction was $40 \%$ for patients with a creatinine clearance of $30-60 \mathrm{~mL} / \mathrm{min}$ and for those on dialysis (Intermittent HemoDialysis - IHD, Slow Low Efficiency Dialysis - SLED and CRRT) and 60\% for patients with a creatinine clearance under $30 \mathrm{~mL} / \mathrm{min}$. On the other side, part of bivalirudin is removed through the hemofilter ${ }^{54}$ and during ECMO dosing requirements can increase when high intensity CRRT is included. ${ }^{55}$ The infusion rate of bivalirudin is usually reported around $0.03-0.2 \mathrm{mg} / \mathrm{kg} / \mathrm{h}$, and the UFH infusion rate range between 20 and $70 \mathrm{IU} / \mathrm{kg} / \mathrm{h}$. ${ }^{46}$ For both drugs, the correct dose is indicated by hemostasis tests. Monitoring the hemostatic system is essential to maintain the correct balance between the necessary coagulation and its possible complications, and many different tests can be used. During UFH and bivalirudin anticoagulation in ECMO patients, Activated Clotting Time (ACT) remains the standard of monitoring. The ACT is usually maintained between 180 and $220 \mathrm{~s}^{46}$ APTT poorly correlates with $\mathrm{ACT}^{56}$ and a range of 1.5 times the baseline value (50-80 s) is considered the target during ECMO. ${ }^{46}$ The anti-Xa activity assessment can be helpful for the definition of the UFH infusion rate. A correct range is between 0.3 and 0.7 IU/mL. ${ }^{57}$
During CRRT, outside the setting of ECMO, regional citrate anticoagulation (RCA) is considered as the standard method. ${ }^{58}$ Citrate chelates the ionized calcium (iCa) in the extracorporeal circuit. ICa is an essential cofactor of many coagulation cascade reactions. Thus, an $\mathrm{iCa}$ reduction (post-filter calcium target $0.25-0.4 \mathrm{mmol} / \mathrm{L}$ ) prevents blood clotting within the circuit.

When ECMO and CRRT are applied at the same time, the commonly used anticoagulation is systemic UFH. CRRT circuit may present a high risk of clotting due to consumption of coagulation factors and to turbulence in high-pressure connections. ${ }^{59}$ Although systemic anticoagulation may be considered adequate in many cases to prevent repeated CRRT circuit clotting, an additional anticoagulant has to be added in some cases. In a recent retrospective study, Giani et $\mathrm{al}^{60}$ enrolled 37 vvECMO patients receiving CRRT with a different anticoagulation approach. Fifteen patients received only systemic UFH (UFH group) and in 22 patients RCA was added (RCA + UFH group) to the CRRT circuit. RCA + UFH group had a lower incidence of CRRT circuit clotting (11\% vs $38 \%$ in the UFH group, $\mathrm{p}<0.001)$ and no significant complications related to the use of RCA have occurred. When RCA is applied on the CRRT circuit, the management of systemic anticoagulation for ECMO does not change. Another beneficial aspect of combined therapies is the possibility, if required due to clinical needs (eg, bleeding complications), of interrupting ECMO systemic anticoagulation while maintaining the regional one preserving the CRRT circuit (Table 3).

\section{Outcomes}

Unsurprisingly, patients requiring ECMO and CRRT have a high mortality rate. The presence of AKI itself rather than the requirement for CRRT is an independent risk factor for mortality in critically ill patients undergoing ECMO. In a retrospective analysis, Kielstein et $\mathrm{al}^{24}$ observed that AKI

Table 3 Systemic Anticoagulation Strategy During ECMO and CRRT: Advantages and Disadvantages

\begin{tabular}{|l|c|l|l|}
\hline \multicolumn{2}{|l|}{ Anticoagulant Strategy } & \multicolumn{1}{c|}{ Advantages } & Disadvantages \\
\hline $\begin{array}{l}\text { Systemic } \\
\text { anticoagulation }\end{array}$ & UFH & $\begin{array}{l}\text { - Less nursing work } \\
\text { - Usable with both integrated and parallel approach }\end{array}$ & $\begin{array}{l}\text { - Less effective } \\
\text { anticoagulation }\end{array}$ \\
\cline { 2 - 5 } $\begin{array}{l}\text { Systemic + Regional } \\
\text { anticoagulation }\end{array}$ & $\begin{array}{c}\text { UFH/ } \\
\text { Bivalirudin }+ \\
\text { RCA }\end{array}$ & $\begin{array}{l}\text { - More effective anticoagulation } \\
\text { - Possibility of interrupting systemic anticoagulation while maintaining the } \\
\text { regional one (eg, bleeding complications) }\end{array}$ & $\begin{array}{l}\text { - Mnure nursing work } \\
\text { line hemofilter }\end{array}$ \\
\hline
\end{tabular}

Abbreviations: UFH, unfractionated heparin; RCA, regional citrate anticoagulation. 
requiring CRRT in patients undergoing ECMO treatment increased 3-month mortality ( $83 \%$ vs $47 \%$, p $<0.001)$. Other authors also confirm the increased mortality in CRRT patients during ECMO (Table 1). ${ }^{6-9,14,23-27}$ In these patients, fluid balance plays a key role in ICU patients' outcomes, and its management is a challenge, particularly during ECMO. To date, it is established that a positive fluid balance is independently associated with mortality ${ }^{6}$ and it should be prevented. As remarked before, CRRT can be useful to timely and accurately control patients' fluid balances, mainly if an early approach is used. ${ }^{24}$

Renal recovery in patients who have received ECMO with CRRT is another critical issue with scant information available. The few studies that address this topic suggest that there is a favorable renal outcome in children and VAECMO survivors (Table 1). ${ }^{6,9,14,18,26}$

A considerable observation is safety of the combination of ECMO with CRRT. A lot of studies in the literature have demonstrated the safety and feasibility of this multiple extracorporeal approach. In a systematic review, Chen et al observed a higher mortality and longer ECMO duration in patients where CRRT was added to ECMO which however reflected a relatively higher severity of illness. They concluded that the combination of ECMO and CRRT resulted a safe and effective technique that improves fluid balance and electrolyte disturbances. ${ }^{11}$ It has been remarked that significant hemolysis, addition of scarcely biocompatible extracorporeal tubing, drug sequestration into circuit inner surface and membranes, and requirement for specifically trained personnel (that may not be available in all centers) may contribute to the potential unsafety of this double extracorporeal support. However, these risks must be counterbalanced with the potential life-saving indication of applying both the treatments and, currently, potential benefits seem to widely overcome the potential risks. Furthermore, many potential unsafety issues appear to be modifiable and can be adjusted once monitoring protocols (ie, fHb check, therapeutic drug monitoring) and appropriately skilled staff operate on these patients.

\section{Conclusion/Future Directions}

The combination of CRRT and ECMO is part of the concept of Multiple Organ Support Therapy (MOST), an extracorporeal approach that is becoming increasingly applied in the ICU. Next-generation machines are needed to achieve harmonization of components, techniques, and operations of MOST.

In this setting, many questions remain open, as how to optimize FO, the best circuits set-ups (integrated vs parallel approach), the optimal anticoagulation strategy, drug posology adjustments (eg, sedatives, vasopressors and antibiotics), the timing to start and to interrupt CRRT. It is possible that with the increased application of MOST in the ICU and the evolution of future technology, more information and data from prospective studies will be available in the literature to optimize the outcomes of these frail patients.

\section{Disclosure}

The authors report no conflicts of interest in this work.

\section{References}

1. ELSO. Guidelines for Cardiopulmonary Extracorporeal Life Support Extracorporeal Life Support Organization, Version 1.4. Ann Arbor, MI, USA; 2017.

2. MacLaren G, Combes A, Bartlett RH. Contemporary extracorporeal membrane oxygenation for adult respiratory failure: life support in the new era. Intensive Care Med. 2012;38(2):210-220. doi:10.1007/ s00134-011-2439-2

3. Dyamenahalli U, Tuzcu V, Fontenot E, et al. Extracorporeal membrane oxygenation support for intractable primary arrhythmias and complete congenital heart block in newborns and infants: short-term and medium-term outcomes. Pediatr Crit Care Med. 2012;13 (1):47-52. doi:10.1097/PCC.0b013e3182196cb1

4. Zangrillo A, Landoni G, Biondi-Zoccai G, et al. A meta-analysis of complications and mortality of extracorporeal membrane oxygenation. Crit Care Resusc. 2013;15(3):172-178.

5. Cheng R, Hachamovitch R, Kittleson M, et al. Complications of extracorporeal membrane oxygenation for treatment of cardiogenic shock and cardiac arrest: a meta-analysis of 1866 adult patients. Ann Thorac Surg. 2014;97(2):610-616. doi:10.1016/j.athoracsur.2013.09.008

6. Dado D, Ainsworth C, Thomas S, et al. Outcomes among patients treated with renal replacement therapy during extracorporeal membrane oxygenation: a single-center retrospective study. Blood Purif. 2020;49(3):341-347. doi:10.1159/000504287

7. Antonucci E, Lamanna I, Fagnoul D, Vincent JL, De Backer D, Silvio Taccone F. The impact of renal failure and renal replacement therapy on outcome during extracorporeal membrane oxygenation therapy. Artif Organs. 2016;40(8):746-754. doi:10.1111/aor.12695

8. Schmidt M, Bailey M, Kelly J, et al. Impact of fluid balance on outcome of adult patients treated with extracorporeal membrane oxygenation. Intensive Care Med. 2014;40(9):1256-1266. doi:10.10 07/s00134-014-3360-2

9. Paden ML, Warshaw BL, Heard ML, Fortenberry JD. Recovery of renal function and survival after continuous renal replacement therapy during extracorporeal membrane oxygenation. Pediatr Crit Care Med. 2011;12(2):153-158. doi:10.1097/PCC.0b013e3181e2a596

10. Barbaro RP, MacLaren G, Boonstra PS, et al. Extracorporeal membrane oxygenation support in COVID-19: an international cohort study of the Extracorporeal Life Support Organization registry. Lancet. 2020;396(10257):1071-1078. doi:10.1016/S0140-6736(20) 32008-0

11. Chen H, Yu R, Yin N, et al. Combination of extracorporeal membrane oxygenation and continuous renal replacement therapy in critically ill patients: a systematic review. Crit Care. 2014;18(6):675. doi:10.1186/s13054-014-0675-x

12. Yan X, Jia S, Meng X, et al. Acute kidney injury in adult postcardiotomy patients with extracorporeal membrane oxygenation: evaluation of the RIFLE classification and the acute kidney injury network criteria. Eur J Cardiothorac Surg. 2010;37:334-338. 
13. Deatrick KB, Mazzeffi MA, Galvagno SM, et al. Breathing life back into the kidney-continuous renal replacement therapy and veno-venous extracorporeal membrane oxygenation. ASAIO J. 2021;67(2):208-212. doi:10.1097/MAT.0000000000001210

14. Devasagayaraj R, Cavarocchi NC, Hirose H. Does acute kidney injury affect survival in adults with acute respiratory distress syndrome requiring extracorporeal membrane oxygenation? Perfusion. 2018;33(5):375-382. doi:10.1177/0267659118755272

15. Selewski DT, Askenazi DJ, Bridges BC, et al. The impact of fluid overload on outcomes in children treated with extracorporeal membrane oxygenation: a multicenter retrospective cohort study. Pediatr Crit Care Med. 2017;18(12):1126-1135. doi:10.1097/PCC.0000000000001349

16. Fleming GM, Askenazi DJ, Bridges BC, et al. A multicenter international survey of renal supportive therapy during ECMO: the kidney intervention during extracorporeal membrane oxygenation (KIDMO) group. ASAIO J. 2012;58(4):407-414. doi:10.1097/MAT.0b013e3182579218

17. Hoover NG, Heard M, Reid C, et al. Enhanced fluid management with continuous venovenous hemofiltration in pediatric respiratory failure patients receiving extracorporeal membrane oxygenation support. Intensive Care Med. 2008;34(12):2241-2247. doi:10.1007/ s00134-008-1200-y

18. Gorga SM, Sahay RD, Askenazi DJ, et al. Fluid overload and fluid removal in pediatric patients on extracorporeal membrane oxygenation requiring continuous renal replacement therapy: a multicenter retrospective cohort study. Pediatr Nephrol. 2020;35(5):871-882. doi:10.1007/s00467-019-04468-4

19. Askenazi DJ, Selewski DT, Paden ML, et al. Renal replacement therapy in critically ill patients receiving extracorporeal membrane oxygenation. Clin J Am Soc Nephrol. 2012;7(8):1328-1336. doi:10.2215/CJN.12731211

20. Lee SW, Yu M-Y, Lee H, et al. Risk factors for acute kidney injury and in-hospital mortality in patients receiving extracorporeal membrane oxygenation. PLoS One. 2015;10(10):e0140674. doi:10.1371/ journal.pone.0140674

21. Haneya A, Diez C, Philipp A, et al. Impact of acute kidney injury on outcome in patients with severe acute respiratory failure receiving extracorporeal membrane oxygenation. Crit Care Med. 2015;43 (9):1898-1906. doi:10.1097/CCM.0000000000001141

22. Wolf MJ, Chanani NK, Heard ML, Kanter KR, Mahle WT. Early renal replacement therapy during pediatric cardiac extracorporeal support increases mortality. Ann Thorac Surg. 2013;96(3):917-922. doi:10.1016/j.athoracsur.2013.05.056

23. Kielstein JT, Heiden AM, Beutel G, et al. Renal function and survival in 200 patients undergoing ECMO therapy. Nephrol Dial Transplant. 2013;28(1):86-90. doi:10.1093/ndt/gfs398

24. Wu MY, Lin PJ, Tsai FC, Haung YK, Liu KS, Tsai F-C. Impact of pre-existing organ dysfunction on extracorporeal life support for non-postcardiotomy cardiopulmonary failure. Resuscitation. 2008;79 (1):54-60. doi:10.1016/j.resuscitation.2008.05.002

25. Thajudeen B, Kamel M, Arumugam C, et al. Outcome of patients on combined extracorporeal membrane oxygenation and continuous renal replacement therapy: a retrospective study. Int $J$ Artif Organs. 2015;38(3):133-137. doi:10.5301/ijao.5000381

26. Aubron C, Cheng AC, Pilcher D, et al. Factors associated with outcomes of patients on extracorporeal membrane oxygenation support: a 5-year cohort study. Crit Care. 2013;17(2):R73. doi:10.1186/ cc12681

27. Lin C, Chen Y, Tsai F, et al. RIFLE classification is predictive of short-term prognosis in critically ill patients with acute renal failure supported by extracorporeal membrane oxygenation. Nephrol Dial Transplant. 2006;21(10):2867-2873. doi:10.1093/ndt/gfl326

28. Chenoweth DE, Cooper SW, Hugli TE, Stewart RW, Blackstone EH, Kirklin JW. Complement activation during cardiopulmonary bypass: evidence for generation of $\mathrm{C} 3 \mathrm{a}$ and $\mathrm{C} 5 \mathrm{a}$ anaphylatoxins. $N$ Engl J Med. 1981;304(9):497-503. doi:10.1056/NEJM198102263040901
29. Bruins P, Te Velthuis H, Yazdanbakhsh AP, et al. Activation of the complement system during and after cardiopulmonary bypass surgery: postsurgery activation involves C-reactive protein and is associated with postoperative arrhythmia. Circulation. 1997;96 (10):3542-3548. doi:10.1161/01.CIR.96.10.3542

30. Donnelly RP, Freeman SL, Hayes MP. Inhibition of IL-10 expression by IFN-gamma up-regulates transcription of TNF-alpha in human monocytes. J Immunol. 1995;155:1420-1427.

31. Jirik FR, Podor TJ, Hirano T, et al. Bacterial lipopolysaccharide and inflammatory mediators augment IL-6 secretion by human endothelial cells. J Immunol. 1989;142:144-147.

32. Gbadegesin R, Zhao S, Charpie J, et al. Significance of hemolysis on extracorporeal life support after cardiac surgery in children. Pediatr Nephrol. 2009;24(3):589-595. doi:10.1007/s00467-008-1047-z

33. Borasino S, Kalra Y, Elam AR, et al. Impact of hemolysis on acute kidney injury and mortality in children supported with cardiac extracorporeal membrane oxygenation. J Extra Corpor Technol. 2018;50 (4):217-224.

34. Toomasian JM, Bartlett RH. Hemolysis and ECMO pumps in the 21st century. Perfusion. 2011;26(1):5-6. doi:10.1177/0267659110396015

35. Ricci Z, Pezzella C, Romagnoli S, et al. High levels of free haemoglobin in neonates and infants undergoing surgery on cardiopulmonary bypass. Interact Cardiovasc Thorac Surg. 2014;19(2):183-187. doi:10.1093/icvts/ivu129

36. Gomez H, Ince C, De Backer D, et al. A unified theory of sepsis-induced acute kidney injury: inflammation, micro-circulatory dysfunction, bioenergetics, and the tubular cell adaptation to injury. Shock. 2014;41(1):3-11. doi:10.1097/SHK.00000000000000052

37. Keckler SJ, Laituri CA, Ostlie DJ, et al. A review of venovenous and venoarterial extracorporeal membrane oxygenation in neonates and children. Eur J Pediatr Surg. 2010;20(1):1-4. doi:10.1055/s-00291231053

38. Han SS, Kim HJ, Lee SJ, et al. Effects of renal replacement therapy in patients receiving extracorporeal membrane oxygenation: a meta-analysis. Ann Thorac Surg. 2015;100(4):1485-1495. doi:10.10 16/j.athoracsur.2015.06.018

39. Murphy HJ, Eklund MJ, Hill J, et al. Early continuous renal replacement therapy during infant extracorporeal life support is associated with decreased lung opacification. J Artif Organs. 2019;22(4): 286-293. doi:10.1007/s10047-019-01119-1

40. Murphy HJ, Cahill JB, Twombley KE, et al. Implementing a practice change: early initiation of continuous renal replacement therapy during neonatal extracorporeal life support standardizes care and improves short-term outcomes. J Artif Organs. 2018;21(1):76-85. doi:10.1007/s10047-017-1000-7

41. Ostermann M, Connor M Jr, Kashani K. Continuous renal replacement therapy during extracorporeal membrane oxygenation: why, when and how? Curr Opin Crit Care. 2018;24(6):493-503. doi:10.1097/MCC.0000000000000559

42. Santiago MJ, Sánchez A, López-Herce J, et al. The use of continuous renal replacement therapy in series with extracorporeal membrane oxygenation. Kidney Int. 2009;76(12):1289-1292. doi:10.1038/ki.2009.383

43. Jacobs R, Honore PM, Spapen HD. Intertwining extracorporeal membrane oxygenation and continuous renal replacement therapy: sense or nonsense? Crit Care. 2015;19(1):145. doi:10.1186/s13054-015-0860-6

44. Sucosky P, Paden ML, Yaganathan AP, et al. Assessment of current continuous hemofiltration systems and development of a novel accurate fluid management system for use in extracorporeal membrane oxygenation. J Med Devices. 2008;2(3):35002. doi:10.1115/ 1.2952818

45. Symons JM, McMahon MW, Karamlou T, Parrish AR, McMullan DM. Continuous renal replacement therapy with an automated monitor is superior to a free-flow system during extracorporeal life support. Pediatr Crit Care Med. 2013;14(9):e404-8. doi:10.1097/ PCC.0b013e31829f5c09 
46. Oliver WC. Anticoagulation and coagulation management for ECMO. Semin Cardiothorac Vasc Anesth. 2009;13(3):154-175. doi:10.1177/1089253209347384

47. Ranucci M, Ballotta A, Kandil H, et al. Bivalirudin-based versus conventional heparin anticoagulation for postcardiotomy extracorporeal membrane oxygenation. Crit Care. 2011;15(6):R275. doi:10.11 $86 / \mathrm{cc} 10556$

48. Bembea MM, Annich G, Rycus P, et al. Variability in anticoagulation management of patients on extracorporeal membrane oxygenation: an international survey. Pediatr Crit Care Med. 2013;14(2):e77-e84. doi:10.1097/PCC.0b013e31827127e4

49. Hirsh J, O’Donnell M, Eikelboom JW. Beyond unfractionated heparin and warfarin: current and future advances. Circulation. 2007;116(5):552-560. doi:10.1161/CIRCULATIONAHA.106.685974

50. Beattie GW, Jeffrey RR. Is there evidence that fresh frozen plasma is superior to antithrombin administration to treat heparin resistance in cardiac surgery? Interact Cardiovasc Thorac Surg. 2014;18 (1):117-120. doi:10.1093/icvts/ivt327

51. Pollak U, Yacobobich J, Tamary H, Dagan O, Manor-Shulman O. Heparin-induced thrombocytopenia and extracorporeal membrane oxygenation: a case report and review of the literature. J Extra Corpor Technol. 2011;43:5-12.

52. Rivosecchi RM, Arakelians AR, Ryan J, et al. Comparison of anticoagulation strategies in patients requiring venovenous extracorporeal membrane oxygenation: heparin versus bivalirudin. Crit Care Med. 2021;49(7):1129-36. doi:10.1097/CCM.0000000000004944

53. Tsu LV, Dager WE. Bivalirudin dosing adjustments for reduced renal function with or without hemodialysis in the management of heparin-induced thrombocytopenia. Ann Pharmacother. 2011;45 (10):1185-1192. doi:10.1345/aph.1Q177
54. Mann MJ, Tseng E, Ratcliffe M, et al. Use of bivalirudin, a direct thrombin inhibitor, and its reversal with modified ultrafiltration during heart transplantation in a patient with heparin-induced thrombocytopenia. J Heart Lung Transplant. 2005;24(2):222-225. doi:10.1016/j.healun.2003.11.401

55. Pieri M, Agracheva N, Bonaveglio E, et al. Bivalirudin versus heparin as an anticoagulant during extracorporeal membrane oxygenation: a case-control study. J Cardiothorac Vasc Anesth. 2013;27 (1):30-34. doi:10.1053/j.jvca.2012.07.019

56. O'Neill AI, McAllister C, Corke CF, Parkin JD. A comparison of five devices for the bedside monitoring of heparin therapy. Anaesth Intensive Care. 1991;19(4):592-596. doi:10.1177/0310057X910190 0423

57. Hirsh J, Raschke R, Warkentin TE, Dalen JE, Deykin D, Poller L. Heparin: mechanism of action, pharmacokinetics, dosing considerations, monitoring, efficacy, and safety. Chest. 1995;108(4 Suppl): 258S-275S. doi:10.1378/chest.108.4_Supplement.258S

58. Kidney Disease Improving Global Outcomes (KDIGO) Acute Kidney Injury Work Group. KDIGO clinical practice guideline for acute kidney injury. Kidney Int. 2012;2:1-138.

59. Baldwin I, Bellomo R, Koch B. Blood flow reductions during continuous renal replacement therapy and circuit life. Intensive Care Med. 2004;30(11):2074-2079. doi:10.1007/s00134004-2440-0

60. Giani M, Scaravilli V, Stefanini F, et al. Continuous renal replacement therapy in venovenous extracorporeal membrane oxygenation: a retrospective study on regional citrate anticoagulation. ASAIO J. 2020;66(3):332-338. doi:10.1097/MAT.000000000000 1003

\section{Publish your work in this journal}

The International Journal of Nephrology and Renovascular Disease is an international, peer-reviewed open-access journal focusing on the pathophysiology of the kidney and vascular supply. Epidemiology, screening, diagnosis, and treatment interventions are covered as well as basic science, biochemical and immunological studies. The manuscript management system is completely online and includes a very quick and fair peer-review system, which is all easy to use. Visit http://www.dovepress.com/testimonials.php to read real quotes from published authors. 